\title{
TEORIA DO ERRO NO DIREITO PENAL BRASILEIRO
}

Andreas Gabriel Ferreira Miranda, Patrícia Pereira Sanna, Rafaela Marques Vilella

Universidade do Oeste Paulista - Unoeste, Curso de Direito, Presidente Prudente, SP. E-mail: andreasferreira50@gmail.com, patriciapimoveis@gmail.com, rafaela.marques.vilella@hotmail.com

\section{RESUMO}

A teoria do erro baseia-se sobre o fato de nossa sociedade atual cometer erros ou ignorância sobre determinados fatos penais. Para isso tornou-se necessária a criação de teorias para determinar até que ponto é tolerável o erro na égide penal. Analisando possibilidade de equivoco criminal, ignorância legal, intenção adversa da conduta nos levam a refletir sobre a limitação dos atos diante da expansão das leis penais.

Palavras-chave: Erro. Direito Penal. Proibição. Tipo. Descriminante.

\section{THEORY OF ERROR IN BRASILIAN CRIMINAL LAW}

\section{ABSTRACT}

The theory of error is based on the fact of our current generation of errors or ignorance about certain criminal facts. For this, it is necessary to create a theory of determination to point the point of view of error and criminal error. Analyzing the possibility of criminal misconception, legal ignorance, adverse intention of conducting first aid on acts before the expansion of criminal laws.

Keywords: Error. Criminal Law. Prohibition. Type. Descending. 


\section{INTRODUÇÃO}

Tratando-se de tema de grande complexidade e que causa grande confusão no mundo penal, o erro dentro das politicas criminais precisa ser tratado com muito cuidado e observado em cada particularidade.

Dentro do capítulo três deste texto, será ilustrado um histórico sobre o erro de tipo e de proibição, além da demonstração de seu conceito. Seguindo, no capítulo quatro será tratado sobre as formas do erro de tipo.

Dentro do capítulo cinco, será abordado o tema referente ao erro de proibição. Seguindo, no capítulo seis, será tratado os casos de descriminantes putativas.

O objetivo do presente trabalho é abordar de maneira sistêmica e organizada o mecanismo do erro dentro do Direito Penal, através de consulta bibliográfica, jurisprudencial e legal sobre o fato narrado.

\section{MÉTODO}

O presente estudo seguirá o método exploratório, com embasamento sobre a legislação, doutrina e jurisprudência, abordando a sistemática do direito material sobre o qual sustenta-se a teoria do erro, exaustivamente, por meio de dedução dialética, chegar ao entendimento do funcionamento e aplicação da referida teoria.

\section{DO ERRO DE TIPO E PROIBIÇÃO HISTÓRICO E CONCEITO}

$\mathrm{Na}$ tentativa de compreender os fundamentos relacionados ao erro, remetemo-nos a era romana, onde houve o início da busca da compreensão do que hoje conhecemos por erro penal. $\mathrm{Na}$ era romana conceituavam-se em duas espécies o erro, sendo elas: erro de fato e de direito.

Quando ingressamos no estudo moderno do erro, nos deparamos com a superação dos entendimentos romanos sobre erro de fato e direito, passando agora a compreendê-los como erro de tipo e de proibição.

O renomado jurista Damásio de Jesus ao tratar da diferenciação histórica e conceitual do erro ensina que (apud. MUNHOZ, 2015, p. 350):

Recaindo sobre as circunstancias que pertencem à figura delituosa, o erro de tipo tanto pode se originar de uma falsa representação de seus elementos materiais, quanto de uma errônea valoração do sujeito acerca de um elemento normativo como seria o caso do erro a respeito da natureza criminosa do fato imputado.

Sendo assim compreende-se que o erro de tipo é aquele que versa sobre os elementares, circunstancias ou qualquer dado da figura típica (GRECO, 2017, p. 438). Já no caso de erro de proibição entende-se ser todo erro sobre a antijuridicidade de uma ação conhecida como típica pelo autor (JESUS apud. MAURACH, 2015, p.351).

As antigas expressões erro de fato e erro de direito não se confundem com as de erro de tipo e de proibição, pois é irrefutável que os conceitos de erro de tipo e de proibição contem maior precisão técnica do que os preceituados pelos romanos. Sendo assim a doutrina moderna surge com uma conceituação mais ampla da encontrada nos primórdios do estudo do erro.

\section{DAS FORMAS DO ERRO DE TIPO}

O erro de tipo previsto no art. 20, caput, do Código Penal, com a seguinte redação: “O erro sobre elemento constitutivo do tipo legal de crime exclui o dolo, mas permite a punição por crime culposo, se previsto em lei." (BRASIL, 1940).

O erro de tipo pode incidir sobre circunstâncias elementares e qualificadoras, quando essenciais, em se tratando de erro acidental sua ocorrência se dá sobre objeto, pessoa e execução. 


\section{ESSENCIAL}

Essa espécie de erro reconhece a possibilidade de defeito no processo de formação cognitiva, sendo assim não idônea a possibilidade de descaracterização do tipo, mas ajuda na punição do agente. (JAPIASSÚ, SOUZA, 2015).

Havendo falsa percepção que impeça o sujeito de compreender a natureza criminosa do fato, alguns elementos como tipo penal ou excludente de ilicitude começam a vir à tona. (JESUS, 2015, p. 352).

Os efeitos do erro de tipo essencial variam de acordo com sua natureza. Segundo Damásio de Jesus (2015, p. 353): "O erro essencial invencível exclui o dolo e a culpa[...] o sujeito não age dolosa ou culposamente. Daí não responde pelo crime doloso ou culposo.". Quando tratamos de erro essencial vencível afirma o referido autor que, há a exclusão do dolo, mas não da culpa, exceto nos casos onde o crime culposo está previsto em lei.

\section{ACIDENTAL}

O erro de tipo acidental, diferente do essencial, versa sobre (error in objecto) erro de objeto, (error in persona) erro de pessoa e (aberratio ictus) erro de execução. Tratando-se do erro de execução, inclui-se como singular o (aberratio criminis), pois ambos versam sobre a anormalidade do delito, sendo considerado delito aberrante (JESUS, 2015, p. 360).

O objeto material do crime pode ser alvo da conduta delituosa quando o sujeito erroneamente supõe que sua conduta recai sobre determinada coisa, sendo que, na realidade, recai sobre outra.

Em se tratando de erro de pessoa, Damásio de Jesus (2015, p.361), diz: “Ocorre quando há erro de representação, em face do qual o sujeito atinge uma pessoa supondo tratar-se da que pretendia ofender".

Aberractio ictus ocorre sempre que houver uma aberração no ataque ou desvio de golpe, fazendo com que o sujeito ataque outra pessoa que não a pretendida.

Segundo Rogério Greco (2017, p.442), o agente incorrerá em (aberratio criminis) quando: "por acidente ou erro na execução do crime, sobrevier resultado diverso do pretendido[...] Aqui, ao contrário da aberratio ictus[...] o erro deverá incidir de coisa para pessoa.".

Preconiza ainda o referido autor que há a hipótese de aberração na causa do resultado, chamada (aberratio causae). Ocorre quando o agente tem o dolo de atingir resultado criminoso e sua conduta leva ao resultado, contudo por uma causa diferente da pretendida.

\section{DO ERRO DE PRIOBIÇÃO}

Doutrinariamente há uma distinção entre erro e ignorância, constituindo-se o erro como conhecimento falso sobre um objeto e ignorância a ausência total do conhecimento do objeto. Os efeitos jurídicos entre erro e ignorância são idênticos.

Conceitua-se erro de proibição quando: "o autor de um fato típico incide por falso conhecimento ou desconhecimento, não tendo possibilidade de verificar que o comportamento é ilícito, sendo inegável tal situação[...] Há dolo (natural), mas ele supõe ilícito seu comportamento.". (SANCTIS; TAVARES; FRANCISCO, 2014).

O desconhecimento da lei não exclui a culpabilidade nos casos do erro de proibição, ou seja, não descaracteriza o tipo penal, porém, acarreta atenuantes como preconiza o art. 65 , II, do Código Penal, com a seguinte redação: "Art. 65 - São circunstâncias que sempre atenuam a pena: II - o desconhecimento da lei;". (BRASIL, 1940).

A subdivisão nessa espécie de erro se dá por meio de existência de causa descriminante, erro sobre a norma pena, erro sobre a existência do dever de agir e limite das descriminantes. 0 erro ainda pode ser inevitável, podendo assim, afastar a culpabilidade, como diz o art. 21, 
parágrafo único do CP. Sendo o erro evitável não há a exclusão do dolo, porém a conduta se torna menos reprovável. (SANCTIS; TAVARES; FRANCISCO, 2014).

\section{DAS DESCRIMINANTES PUTATIVAS}

Ocorrem as descriminantes quando o sujeito, é levado ao erro diante do caso concreto há um supor sobre o agir em face de uma causa que exclui a ilicitude. Disciplinada pelo art. 23, caput, do $C P$, enumera quatro causas onde a antijuricidade é excluída.

Art. 23 - Não há crime quando o agente pratica o fato:

I - em estado de necessidade;

II - em legítima defesa;

III - em estrito cumprimento de dever legal ou no exercício regular de direito. (BRASIL, 1940).

Segundo o entendimento de Rogério Greco (2017, p. 443): “Quando falamos em descriminantes putativas, estamos querendo dizer que o agente atuou supondo encontrar-se numa situação de legítima defesa, de estado de necessidade, de estrito cumprimento de dever legal ou de exercício regular de direito.". Sendo assim, a situação de fato apenas existe na mente do agente, se existisse de fato a ação seria legítima.

Incidindo o erro sobre pressuposto de fato da excludente, tratar-se-á de erro de tipo, como exclusão de dolo e culpa, sendo evitável, exclui-se o dolo, podendo responder por culpa. As descriminantes putativas derivadas de erro de tipo precisam que o erro seja justificado pelas circunstancias, devendo ter o cuidado a respeito do erro ser vencível e invencível. (JESUS, 2015, p. 359).

\section{CONCLUSÃO}

Diante do exposto, conclui-se que a teoria do erro baseia-se na interação entre diversos fatores, cognitivos e legais. Nos casos cognitivos leva-se em conta a compreensão do agente diante do fato delituoso sobre sua maneira de agir e compreender a existência ou não de um fato criminoso, levando em consideração o caso onde o agente desconheça a lei, surge o que chamamos de erro de proibição, que conduz a excludente de ilicitude.

Havendo erro em questão de elementares, qualificadoras ou quaisquer circunstancias sobre o tipo penal nos deparamos com o erro de tipo. Conduzindo a exclusão do dolo e da culpa tratando-se de erro escusável, ou então a responsabilidade do agente torna-se a titulo de culpa, quando previsto em lei, nos casos de erro inescusável.

A importância do mecanismo para conceituação e entendimento do erro dentro do Direito Penal, remete a possibilidade de diante de um fato concreto o agente criminoso ter sua pena atenuada ou, dependendo do erro, excluir-se a característica dolosa fazendo com que se cumpra a titulo de culpa, ou vice-versa.

\section{REFEÊNCIAS}

BRASIL, Código Penal. Diário Oficial da União, Brasilia, DF, 07 dez. 1940. Disponível em: <http://www.planalto.gov.br/ccivil_03/decreto-lei/Del2848compilado.htm>. Acesso em: 16 ago. 2018.

CECHINEL, Liliana. O estudo da teoria do erro no direito penal. Jus. Curitiba: jul. 2017. Disponível em: <https://jus.com.br/artigos/58883/o-estudo-da-teoria-do-erro-no-direito-penal>. Acesso em: 16 ago. 2018

GRECO, Rogério. Curso de direito penal: parte geral. v.1. 19 ed. São Paulo: Impetus. 2017. 
JAPIASSÚ, Carlos; SOUZA, Artur. Curso de direito penal: parte geral. V.1. 2 ed. São Paulo: Forense, 2015.

JESUS, Damásio de. Direito penal: parte geral. V.1. 36 ed. São Paulo: Saraiva. 2015. P. 349-368.

SANCTIS, F.; TAVARES, A. R.; FRANCISCO, J. Série Carreiras Federais- Direito penal: parte geral. São Paulo: Método. Rio de Janeiro: Forense, 2014. 